\title{
Effects of irradiated cell conditioned medium on the response of human lung cancer cells to anticancer treatment in vitro
}

\author{
HIRONORI YOSHINO $^{1}$, MIKOTO NAWAMAKI ${ }^{2}$, KANNA MURAKAMI $^{2}$ and IKUO KASHIWAKURA ${ }^{1}$ \\ ${ }^{1}$ Department of Radiation Science, Hirosaki University Graduate School of Health Sciences; ${ }^{2}$ Department of \\ Radiological Technology, Hirosaki University School of Health Sciences, Hirosaki, Aomori 036-8564, Japan
}

Received March 23, 2019; Accepted April 23, 2019

DOI: $10.3892 /$ wasj.2019.11

\begin{abstract}
Ionizing radiation induces a cellular response not only in the irradiated cells, but also in the neighboring non-irradiated cells, and this effect is known as the radiation-induced bystander effect. The irradiated cells transmit signals to the non-irradiated cells via gap junctions or soluble factors, exerting biological effects on the neighboring non-irradiated cells. In this study, we investigated the effects of irradiated cell conditioned medium (ICCM) on the response of human lung cancer cells (A549 and H1299) to anticancer treatment. First, we analyzed the effects of ICCM on the induction of apoptosis by anticancer treatment (ionizing radiation or gefitinib). Human lung cancer cells were cultured with ICCM from non-irradiated and 8 Gy-irradiated cells and, subsequently, exposed to $8 \mathrm{~Gy} \mathrm{X-ray.} \mathrm{In} \mathrm{the} \mathrm{A549} \mathrm{cells,}$ the proportion of Annexin $\mathrm{V}^{+}$apoptotic cells was significantly lower in the cells treated with ICCM from 8 Gy-irradiated cells when compared with that in the cells treated with ICCM from non-irradiated cells $(\mathrm{P}<0.05)$, whereas this effect was not observed in the H1299 cells. Furthermore, no significant difference in the proportion of Annexin $\mathrm{V}^{+}$cells was noted following treatment with gefitinib, an inhibitor of the epidermal growth factor receptor tyrosine kinase, between the cells treated with ICCM from non-irradiated cells and those treated with ICCM from the 8 Gy-irradiated cells. We then examined the effects of ICCM on the migration of A549 cells by scratch assay. ICCM from the 8 Gy-irradiated cells enhanced the migration of the 8 Gy-irradiated cells, but not
\end{abstract}

Correspondence to: Dr Hironori Yoshino, Department of Radiation Science, Hirosaki University Graduate School of Health Sciences, 66-1 Hon-cho, Hirosaki, Aomori 036-8564, Japan E-mail: hyoshino@hirosaki-u.ac.jp

Abbreviations: DMSO, dimethyl sulfoxide; EGFR, epidermal growth factor receptor; ICCM, irradiated cell conditioned medium; PI, propidium iodide; SD, standard deviation; TGF- $\beta$, transformation growth factor- $\beta$

Key words: ionizing radiation, bystander effect, irradiated cell conditioned medium, gefitinib, apoptosis, migration that of the non-irradiated cells. Taken together, these results suggest that cancer cells treated with ICCM exhibit resistance to ionizing radiation in terms of apoptosis and cellular migration, although this phenomenon depends on the cell type.

\section{Introduction}

Ionizing radiation exerts biological effects, such as cell death and chromosomal aberration due to the direct radiation of the cells. However, evidence suggests that this radiation affects not only the cells irradiated directly, but also the surrounding non-irradiated cells (1-3). This response, known as the non-targeted effect, includes genomic instability and other radiation-induced bystander effects. Genomic instability refers to biological effects, such as delayed gene mutations and chromosomal aberrations that occur in the progeny of the irradiated cells (3), whereas radiation-induced bystander effects are caused by the transmission of signals from the irradiated cells to the non-irradiated cells via gap junctions or soluble factors $(1,2)$. Various factors, such as transformation growth factor- $\beta$ (TGF- $\beta$ ), tumor-necrosis factor- $\alpha$, and reactive oxygen species have been reported to be possible candidate bystander factors (4). In general, to examine the bystander effects mediated by soluble factors in vitro, non-irradiated cells are co-cultured with irradiated cells or cultured in the presence of irradiated cell conditioned medium (ICCM). Non-irradiated cells co-cultured with irradiated cells or treated with ICCM have been reported to undergo various biological effects, such as DNA double-strand breaks and apoptosis, generally observed in irradiated cells $(1,3)$.

Radiation therapy is widely used in the the treatment of various types of cancer. Although radiation therapy is considered to control the tumor cells locally, there is evidence to indicate additional systemic antitumor effects of this therapy $(5,6)$; these effects have been referred to as the abscopal effect. In the abscopal effect, the reduction or disappearance of tumors occurs not only in the irradiated lesions, but also in the non-irradiated lesions, suggesting that signals from irradiated tissues can affect the unirradiated tissues outside of the irradiated volume. There is recent evidence to suggest the involvement of the immune system in the abscopal effect (7). Briefly, irradiated tumors release immunostimulatory molecules, such as inflammatory cytokines and damage-associated molecular patterns, which are endogenous molecules released 
due to cellular damage. The released signals activate the innate immune system, leading to T-cell-mediated cytotoxicity against tumors in non-irradiated lesions (8).

The factors released from irradiated cells exert biological effects, such as the induction of apoptosis and activate antitumor immunity, which may prove beneficial for the treatment of cancers $(5,9,10)$. However, little is known about the effects of factors released from irradiated cells on the response of cancer cells to anticancer treatment. Therefore, the present study investigated the effects of ICCM on the response of human lung cancer cells to anticancer treatment in terms of the induction of apoptosis and cellular migration.

\section{Materials and methods}

Reagents. Dimethyl sulfoxide (DMSO) and propidium iodide (PI) were purchased from Sigma-Aldrich (St. Louis, MO, USA). Gefitinib was purchased from Selleckchem (Houston, TX, USA).

Cells and cell culture. Human lung cancer cell lines A549 and H1299 cells were purchased from the American Type Culture Collection (ATCC; Manassas, VA, USA). The cells were maintained at $37^{\circ} \mathrm{C}$ in a humidified atmosphere containing $5 \% \mathrm{CO}_{2}$ and cultured in RPMI-1640 medium (Gibco ${ }^{\circledR}$; Invitrogen/Thermo Fisher Scientific, Waltham, MA, USA) supplemented with $1 \%$ penicillin/streptomycin $\left(\mathrm{Gibco}^{\circledR}\right)$ and $10 \%$ heat-inactivated fetal bovine serum (Japan Bioserum Co., Ltd., Nagoya, Japan).

In vitro irradiation. The cells were irradiated $(150 \mathrm{kVp} ; 20 \mathrm{~mA}$; $0.5 \mathrm{~mm} \mathrm{Al}$ and $0.3 \mathrm{~mm} \mathrm{Cu}$ filters) using an X-ray generator (MBR 1520R 3; Hitachi, Ltd., Tokyo, Japan) at a distance of $45 \mathrm{~cm}$ from the focus and a dose rate of 1.01-1.07 Gy/min.

Medium transfer experiments. Medium transfer experiments were performed, as previously reported (11). A schematic illustration of the medium transfer experiments is presented in Fig. 1. Approximately $2.4 \times 10^{5}$ cells were seeded onto 35-mm culture dishes (Iwaki, Chiba, Japan) and cultured for $5 \mathrm{~h}$ at $37^{\circ} \mathrm{C}$ to promote their adherence to the dish. The cells were then exposed to $8 \mathrm{~Gy}$ X-ray and cultured for $24 \mathrm{~h}$ at $37^{\circ} \mathrm{C}$. The conditioned medium was then collected by centrifugation (180 x $\mathrm{g}$ for $5 \mathrm{~min}$ at room temperature) wherein, the supernatant was collected and filtered using a $0.45-\mu \mathrm{m}$ syringe filter (2053-025; Iwaki) to remove cells and debris. The filtrated cell conditioned medium (hereafter referred to as ICCM) was used in the subsequent experiments.

One day prior to the collection of the ICCM, approximately $6.0 \times 10^{4}$ cells were seeded onto $35-\mathrm{mm}$ culture dishes and cultured overnight at $37^{\circ} \mathrm{C}$ to allow for their adherence to the dish. On the following day, the medium was aspirated and ICCM was added to the 35-mm culture dishes. After $2 \mathrm{~h}$ of culturing at $37^{\circ} \mathrm{C}$, the cells were exposed to $8 \mathrm{~Gy}$ X-ray or $20 \mu \mathrm{M}$ of gefitinib, which was added to the culture medium. DMSO $(0.1 \%)$ was used as a vehicle control for gefitinib. Following 3 days of culture, the cells were harvested using $0.1 \%$ trypsin-ethylene diamine tetraacetic acid (Gibco ${ }^{\circledR}$; Thermo Fisher Scientific) to perform the apoptosis assay.

Apoptosis assay. Apoptosis was analyzed using Annexin V-FITC, PI and Annexin V binding buffer (all BioLegend Inc., San Diego,
CA, USA), as reported previously (12). The stained cells were analyzed by performing flow cytometry (Cytomics FC500 with CXP software version 2; Beckman Coulter, Inc., Brea, CA, USA).

Scratch assay. The A549 cells were cultured in a 24-well plate (BD Falcon; BD Biosciences, Franklin Lakes, NJ, USA) until they reached approximately $90 \%$ confluence. The cell monolayer was scratched using a yellow tip. After the culture medium containing floating cells was aspirated, ICCM (500 $\mu \mathrm{l})$ was added to the plate. The cell-free scratched area was measured using an Olympus LX71 microscope and DP2-BSW software version 2.1 (both Olympus, Tokyo, Japan) immediately, and at 24 and $48 \mathrm{~h}$ after scratching, and the percentage of wound closure area was calculated. In some experiments, the cells were exposed to 8 Gy X-ray at $2 \mathrm{~h}$ following the addition of ICCM.

Statistical analysis. Data are presented as the means \pm standard deviation (SD). Comparisons between the control and experimental groups were performed using a two-sided Student's t-test or a two-sided Mann-Whitney U test depending on the data distribution. Multiple data were analyzed using one-factor analysis of variance followed by the Tukey-Kramer test. Differences were considered statistically significant at $\mathrm{P}<0.05$. All statistical analyses were performed using Excel 2016 software version 1903 (Microsoft, USA), with an add-on software Statcel 4 (OMS Publishing, Inc., Tokyo, Japan).

\section{Results}

Effects of ICCM on the induction of apoptosis by X-ray irradiation. We examined the effects of ICCM on the induction of apoptosis of the A549 and H1299 cells following ionizing radiation. Yang et al previously reported that the cell conditioned medium from irradiated A549 cells exerted cyototoxic effects against non-irradiated A549 cells (9). However, under the present experimental conditions, at 0 Gy irradiation no significant differences in the proportion of Annexin $\mathrm{V}^{+}$apoptotic cells were observed between the cells treated with ICCM from the non-irradiated cells and those treated with ICCM from 8 Gy-irradiated cells (Fig. 2A), as we have previously reported (11). In the A549 cells, the proportion of Annexin $\mathrm{V}^{+}$apoptotic cells was significantly increased following exposure to $8 \mathrm{~Gy} \mathrm{X}$-ray when compared to the cells exposed to 0 Gy X-ray after being cultured with ICCM from irradiated and non-irradiated cells $(\mathrm{P}<0.01)$. Notably, the proportion of Annexin $\mathrm{V}^{+}$apoptotic cells was significantly lower in the 8 Gy-irradiated cells treated with ICCM from 8 Gy-irradiated cells when compared with those treated with ICCM from non-irradiated cells ( $\mathrm{P}<0.05$; Fig. 2A). However, this effect was not observed in the experiments using the H1299 cells (Fig. 2B) and ICCM from 2 Gy-irradiated cells (data not shown). These results suggest that the effects of ICCM vary depending on the cell type, as well as the radiation dose (13).

Effects of ICCM on the induction of apoptosis by gefitinib treatment. Inhibitors of the epidermal growth factor receptor (EGFR) tyrosine kinase, such as gefitinib have been used in the treatment of lung cancer (14). Therefore, in this study, we examined the effect of ICCM on the induction of apoptosis by gefitinib in the A549 and H1299 cells. As shown in Fig. 3, gefitinib treatment significantly increased the proportion of Annexin $\mathrm{V}^{+}$apoptotic 


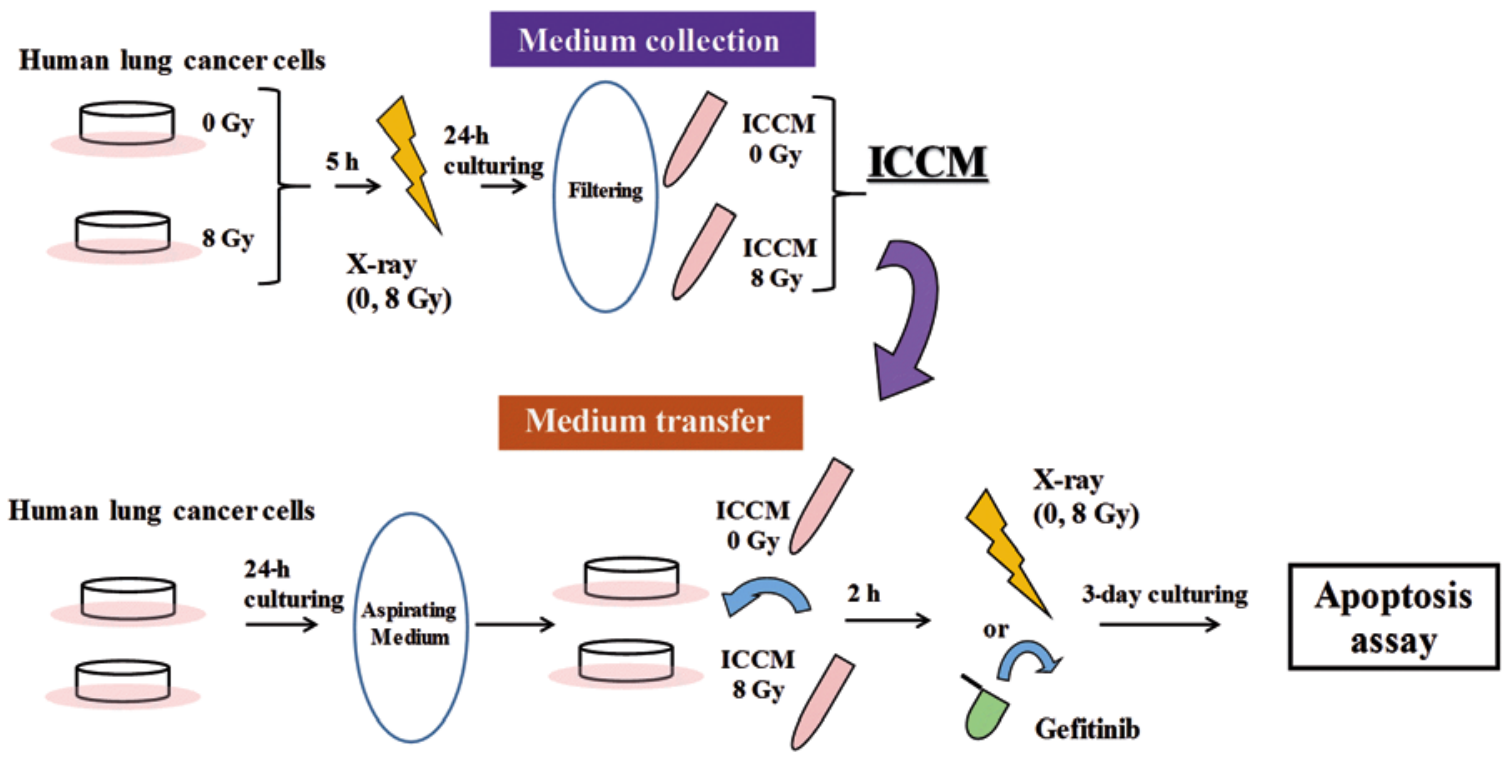

Figure 1. Schematic illustration of medium transfer experiments. The procedures for the collection of ICCM and treatment of cells with ICCM. ICCM, irradiated cell conditioned medium.
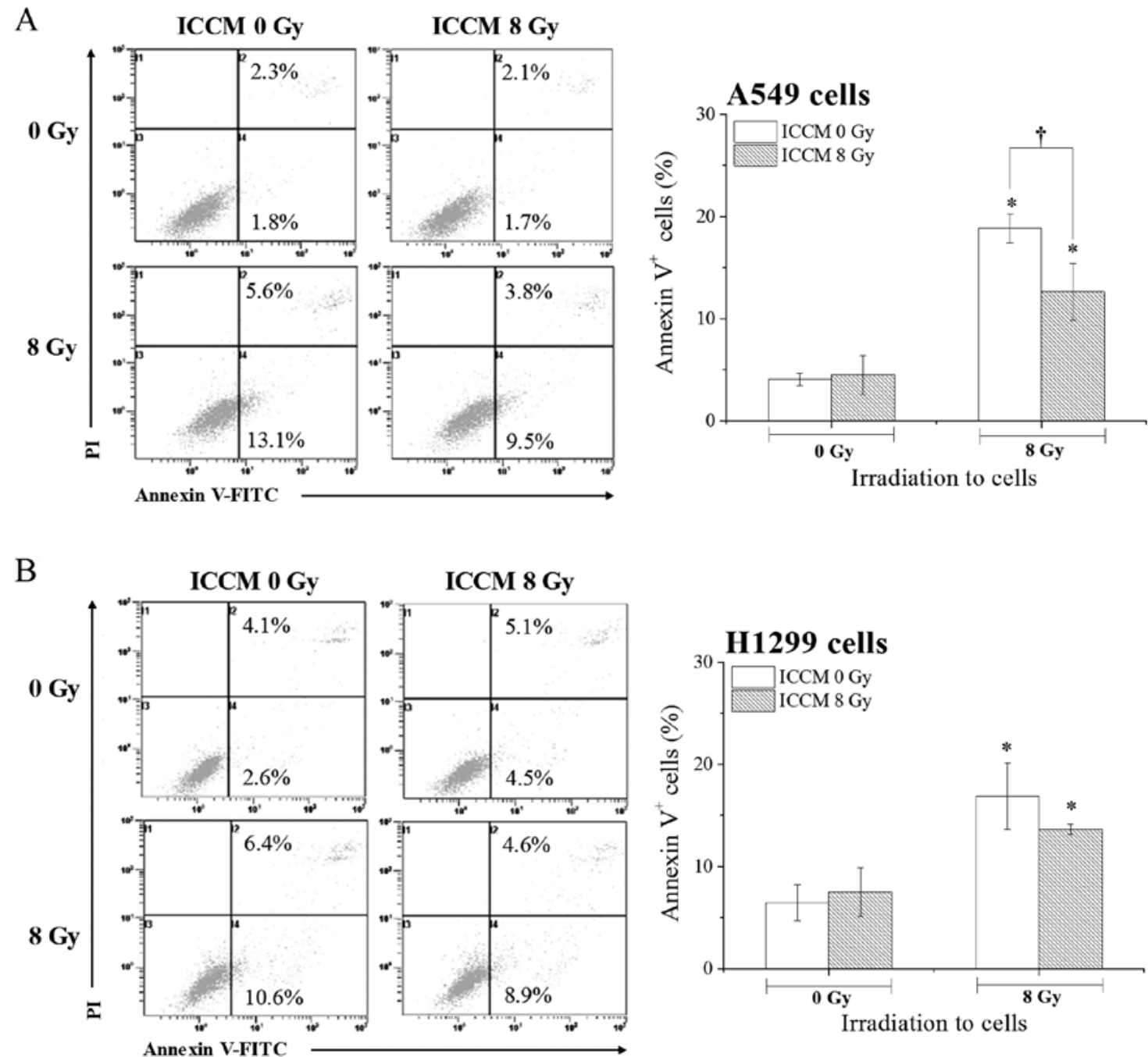

Figure 2. Effects of ICCM on apoptosis in cells exposed to X-ray. (A) A549 and (B) H1299 cells cultured in the presence of ICCM were exposed to 8 Gy X-ray irradiation. After 3 days of culturing, the cells were harvested for apoptosis assay. (Left panels) Representative cytograms of Annexin V/PI staining with inset numbers indicating the percentage of Annexin $\mathrm{V}^{+} / \mathrm{PI}^{-}$and Annexin $\mathrm{V}^{+} / \mathrm{PI}^{+}$cells. (Right panels) Percentages of Annexin $\mathrm{V}^{+}$cells (sum of Annexin $\mathrm{V}^{+} / \mathrm{PI}^{-}$and Annexin $\mathrm{V}^{+} / \mathrm{PI}^{+}$cells) are presented as the mean \pm standard deviation from at least 3 independent experiments. ${ }^{*} \mathrm{P}<0.01$, compared with $0 \mathrm{~Gy}$; ${ }^{\dagger} \mathrm{P}<0.05$. ICCM, irradiated cell conditioned medium. 
A

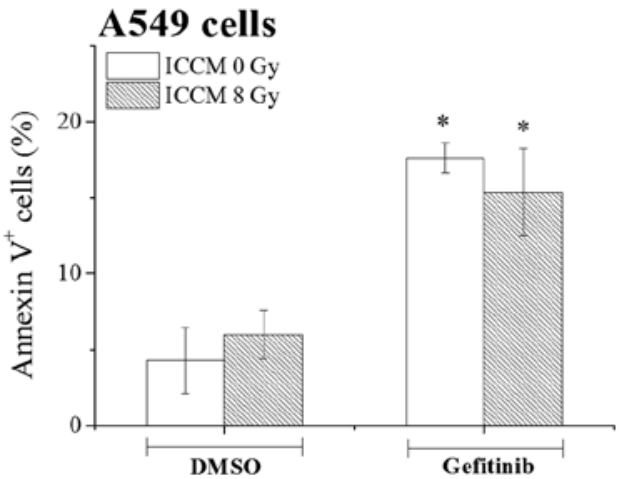

B

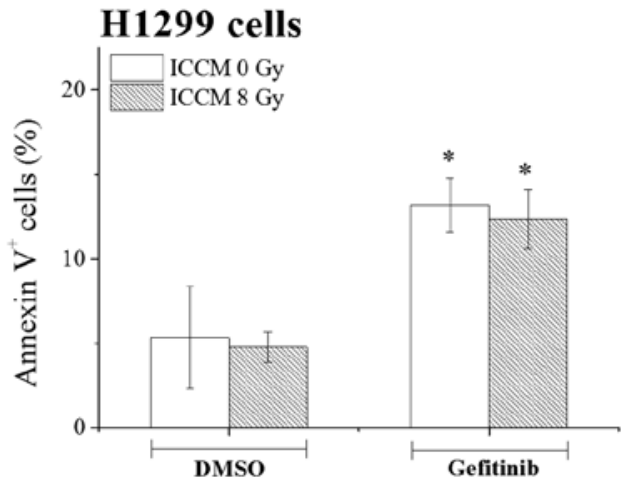

Figure 3. Effects of ICCM on the apoptosis of cells treated with gefitinib. (A) A549 and (B) H1299 cells cultured in the presence of ICCM were treated with gefitinib. After 3 days of culturing, the cells were harvested for apoptosis assay. The percentages of Annexin $\mathrm{V}^{+}$cells are presented as the means \pm standard deviation from 3 independent experiments. "P<0.01, compared with DMSO. ICCM, irradiated cell conditioned medium; DMSO, dimethyl sulfoxide.

A
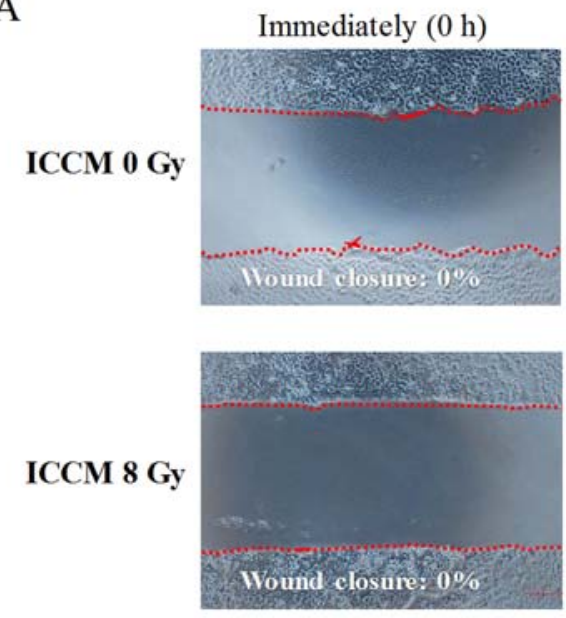

B

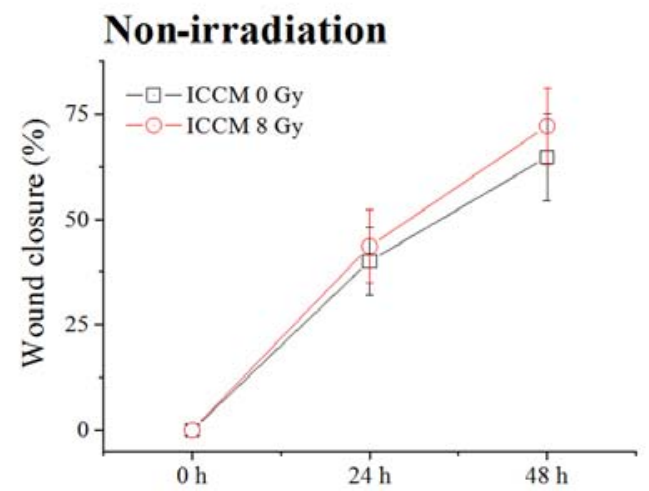

$24 \mathrm{~h}$ after scratch
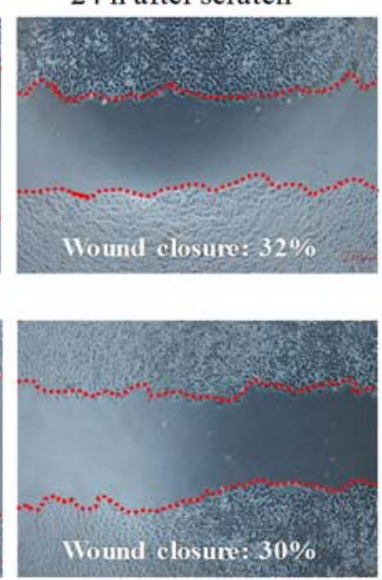

C

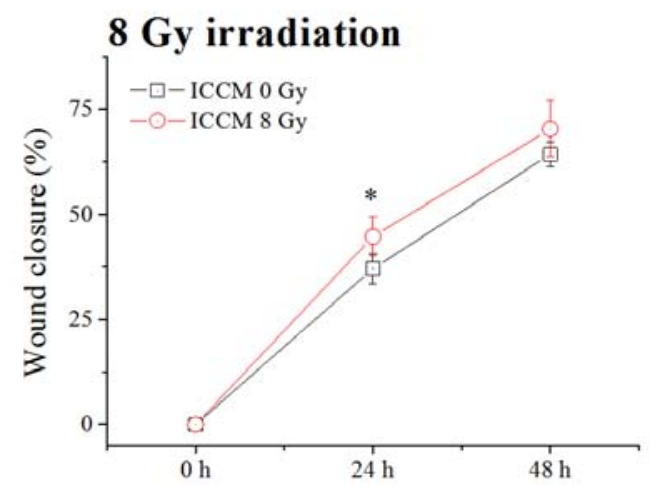

Figure 4. Effects of ICCM on cellular migration. (A and B) The scratched A549 cell monolayer was cultured with ICCM. Following 24 and 48 h of culturing, the percentages of wound closure area were calculated. (A) Representative images of the scratch assay are shown. The wound area is indicated by a red dotted line, and inset numbers are the percentages of wound closure area. (B) The percentages of the wound closure area presented as the means \pm standard deviation of 3 independent experiments performed in triplicate. (C) The scratched A549 cell monolayer was exposed to 8 Gy X-ray in the presence of ICCM. After 24 and $48 \mathrm{~h}$ of culturing, the percentages of the wound closure area were calculated. The percentages of the wound closure area are presented as the means \pm standard deviation of 3 independent experiments performed in triplicate. " $\mathrm{P}<0.01$, compared with ICCM 0 Gy. ICCM, irradiated cell conditioned medium.

A549 and $\mathrm{H} 1299(\mathrm{P}<0.05)$ when compared with the cells treated with DMSO. However, in contrast to the results obtained with X-ray irradiation (Fig. 2), no significant differences in the proportion of Annexin $\mathrm{V}^{+}$apoptotic cells were noted between ICCM obtained from non-irradiated cells and that from irradiated cells (Fig. 3).
Effect of ICCM on cellular migration. As shown in Fig. 4, both ICCM from non-irradiated cells and that from 8 Gy-irradiated cells exerted minimal effects on the migration of the non-irradiated A549 cells. Additionally, no significant difference in the wound closure area was observed between the non-irradiated cells and 8 Gy-irradiated 
cells (ICCM 0 Gy in Fig. 4B vs. ICCM 0 Gy in Fig. 4C). However, as shown in Fig. $4 \mathrm{C}$, the wound closure area in the 8 Gy-irradiated A549 cells at $24 \mathrm{~h}$ after the scratch was made was significantly greater in the cells treated with ICCM from irradiated cells when compared with those from non-irradiated cells $(\mathrm{P}<0.01)$.

\section{Discussion}

The factors released from irradiated cells induce various biological effects, such as cell death and inflammatory responses, and these effects may be preferential for cancer treatment. In this study, we investigated the effects of ICCM from irradiated human lung cancer cells on the response to anticancer treatment (ionizing radiation or gefitinib). Although ICCM did not induce the apoptosis of non-irradiated cells in the current study, it attenuated the induction of apoptosis by ionizing radiation, but not by gefitinib, depending on the cell type. We also demonstrated that ICCM enhanced the migration of 8 Gy-irradiated cells, but not that of non-irradiated cells. Taken together, these results suggest that cancer cells treated with ICCM exhibit resistance to ionizing radiation in terms of apoptosis and cellular migration. In line with our results, Iyer and Lehnert reported that clonogenic survival after $\gamma$-irradiation ( $2 \mathrm{~Gy}$ or $4 \mathrm{~Gy}$ ) in normal human lung fibroblasts (HFL-1) was increased when the cells were treated with ICCM (15). In this study, we did not determine the underlying mechanisms through which ICCM treatment increased the resistance to ionizing radiation. Nonetheless, some factors released as bystander signals, such as interleukin- 6 are known to induce radioresistance $(16,17)$. Therefore, it is possible that these cytokines were involved in the ICCM-induced resistance to ionizing radiation in this study.

It is known that the cells exposed to a low radiation priming dose exhibit resistance to a subsequent high dose of radiation, namely radiation-induced adaptive response. This effect is observed at both the cellular and individual level, and it seems to occur in a $p 53$-dependent manner $(18,19)$. p53 is a tumor suppressor gene that plays critical roles in cellular responses, such as the induction of apoptosis following DNA damage, including ionizing radiation (20). In this study, we found that ICCM treatment attenuated the induction of apoptosis of $p 53$-wild type A549 cells, but not that of p53-null H1299 cells, following ionizing radiation. Therefore, the cell type specific-effect of ICCM, which is similarly to a priming low-dose irradiation, may be dependent on the $p 53$ status.

Tumor cells sometimes acquire radioresistance, a major cause of treatment failure during radiation therapy (21). In the current study, ICCM treatment resulted in resistance to ionizing radiation, whereas no such effect was noted with gefitinib. This may be attributed to the differences in the mechanisms of action between gefitinib and ionizing radiation. Gefitinib induces tumor growth arrest and apoptosis by inhibiting EGFR signaling (22), while ionizing radiation exerts cell-killing effects by inducing DNA damage (23). Kuwahara et al reported that radioresistant cancer cells established by daily repeated irradiation in vitro showed cross-resistance to X-rays and the anti-microtubule agent, docetaxel (24). Further studies are warranted to investigate the effects of ICCM on the anticancer effects of various types of anticancer agents.

For a favorable prognosis of cancer patients, it is important to control tumor migration and invasion. Akino et al reported that carbon-ion beam and X-ray irradiation suppressed the migration and invasion of human lung cancer cells in vitro (25). In the present study, 8 Gy X-ray irradiation had very minimal effects on cell migration. However, we observed that ICCM enhanced the migration of 8 Gy-irradiated cells, but not that of the non-irradiated cells. Zhou et al reported that $2 \mathrm{~Gy} \gamma$-irradiation promoted the migration and invasion of cancer cells, including A549 cells, via TGF- $\beta$-mediated epithelial-mesenchymal transition (26). TGF- $\beta$ is known as a bystander signal (27) and may possibly facilitate the ICCM-mediated cellular migration of irradiated cells. The involvement of TGF- $\beta$ in the increase in cellular migration of irradiated cells by ICCM treatment warrants further investigation in the future.

In conclusion, although the present study is limited in terms of the in vitro nature of the analysis, our results suggest that cancer cells treated with ICCM exhibit resistance to ionizing radiation, which may be unfavorable for cancer treatment. Therefore, further studies clarifying the underlying mechanisms involved are required to achieve an effective treatment strategy for cancer.

\section{Acknowledgements}

The authors would like to thank Enago (www.enago.jp) for the English language review.

\section{Funding}

The present study was supported by JSPS KAKENHI (grant no. JP15K09985).

\section{Availability of data and materials}

The datasets used and/or analyzed during the current study are available from the corresponding author on reasonable request.

\section{Authors' contributions}

HY and IK initiated the research. HY, MN and KM performed the experiments, and collected and analyzed the data. HY and IK wrote, reviewed, and revised the manuscript. All authors have read and approved the final manuscript.

\section{Ethics approval and consent to participate}

Not applicable.

\section{Patient consent for publication}

Not applicable.

\section{Competing interests}

The authors declare that they have no competing interests. 


\section{References}

1. Tomita M and Maeda M: Mechanisms and biological importance of photon-induced bystander responses: Do they have an impact on low-dose radiation responses. J Radiat Res (Tokyo) 56: 205-219, 2015.

2. Hamada N, Maeda M, Otsuka K and Tomita M: Signaling pathways underpinning the manifestations of ionizing radiation-induced bystander effects. Curr Mol Pharmacol 4: 79-95, 2011.

3. Matsumoto H, Tomita M, Otsuka K, Hatashita M and Hamada N: Nitric oxide is a key molecule serving as a bridge between radiation-induced bystander and adaptive responses. Curr Mol Pharmacol 4: 126-134, 2011

4. Kadhim MA and Hill MA: Non-targeted effects of radiation exposure: Recent advances and implications. Radiat Prot Dosimetry 166: 118-124, 2015

5. Grass GD, Krishna N and Kim S: The immune mechanisms of abscopal effect in radiation therapy. Curr Probl Cancer 40: 10-24, 2016.

6. Siva S, MacManus MP, Martin RF and Martin OA: Abscopal effects of radiation therapy: A clinical review for the radiobiologist. Cancer Lett 356: 82-90, 2015.

7. Levy A, Chargari C, Marabelle A, Perfettini JL, Magné N and Deutsch E: Can immunostimulatory agents enhance the abscopal effect of radiotherapy? Eur J Cancer 62: 36-45, 2016.

8. Demaria S, Ng B, Devitt ML, Babb JS, Kawashima N, Liebes L and Formenti SC: Ionizing radiation inhibition of distant untreated tumors (abscopal effect) is immune mediated. Int J Radiat Oncol Biol Phys 58: 862-870, 2004.

9. Yang S, Xu J, Shao W, Geng C, Li J, Guo F, Miao H, Shen W, Ye T, Liu Y, et al: Radiation-induced bystander effects in A549 cells exposed to $6 \mathrm{MV}$ X-rays. Cell Biochem Biophys 72 877-882, 2015

10. Jiang Y, Chen X, Tian W, Yin X, Wang $J$ and Yang H: The role of TGF- $\beta 1-m i R-21-R O S$ pathway in bystander responses induced by irradiated non-small-cell lung cancer cells. Br J Cancer 111: 772-780, 2014.

11. Yoshino H, Murakami K, Nawamaki M and Kashiwakura I: Effects of Nrf2 knockdown on the properties of irradiated cell conditioned medium from A549 human lung cancer cells. Biomed Rep 8: 461-465, 2018.

12. Yoshino H, Konno H, Ogura K, Sato Y and Kashiwakura I: Relationship between the regulation of caspase-8-mediated apoptosis and radioresistance in human THP-1-derived macrophages. Int J Mol Sci 19: E3154, 2018.

13. Morgan WF and Sowa MB: Non-targeted effects induced by ionizing radiation: Mechanisms and potential impact on radiation induced health effects. Cancer Lett 356: 17-21, 2015.

14. Kucharczuk CR, Ganetsky A and Vozniak JM: Drug-drug interactions, safety, and pharmacokinetics of EGFR tyrosine kinase inhibitors for the treatment of non-small cell lung cancer. J Adv Pract Oncol 9: 189-200, 2018.
15. Iyer $\mathrm{R}$ and Lehnert BE: Low dose, low-LET ionizing radiation-induced radioadaptation and associated early responses in unirradiated cells. Mutat Res 503: 1-9, 2002.

16. Pasi F, Facoetti A and Nano R: IL-8 and IL-6 bystander signalling in human glioblastoma cells exposed to gamma radiation. Anticancer Res 30: 2769-2772, 2010.

17. Tamari Y, Kashino G and Mori H: Acquisition of radioresistance by IL- 6 treatment is caused by suppression of oxidative stress derived from mitochondria after $\gamma$-irradiation. J Radiat Res (Tokyo) 58: 412-420, 2017.

18. Takahashi A, Matsumoto $\mathrm{H}$ and Ohnishi T: $\mathrm{Hdm} 2$ and nitric oxide radicals contribute to the p53-dependent radioadaptive response. Int J Radiat Oncol Biol Phys 71: 550-558, 2008.

19. Yonezawa M: Induction of radio-resistance by low dose X-irradiation. Yakugaku Zasshi 126: 833-840, 2006 (In Japanese).

20. Lakin ND and Jackson SP: Regulation of p53 in response to DNA damage. Oncogene 18: 7644-7655, 1999.

21. Kim JJ and Tannock IF: Repopulation of cancer cells during therapy: An important cause of treatment failure. Nat Rev Cancer 5: 516-525, 2005.

22. Rho JK, Choi YJ, Ryoo BY, Na II, Yang SH, Kim CH and Lee JC: p53 enhances gefitinib-induced growth inhibition and apoptosis by regulation of Fas in non-small cell lung cancer. Cancer Res 67: 1163-1169, 2007.

23. Klammer H, Mladenov E, Li F and Iliakis G: Bystander effects as manifestation of intercellular communication of DNA damage and of the cellular oxidative status. Cancer Lett 356: 58-71, 2015.

24. Kuwahara Y, Roudkenar MH, Suzuki M, Urushihara Y, Fukumoto M, Saito Y and Fukumoto M: The involvement of mitochondrial membrane potential in cross-resistance between radiation and docetaxel. Int J Radiat Oncol Biol Phys 96: 556-565, 2016.

25. Akino Y, Teshima T, Kihara A, Kodera-Suzumoto Y, Inaoka M, Higashiyama S, Furusawa Y and Matsuura N: Carbon-ion beam irradiation effectively suppresses migration and invasion of human non-small-cell lung cancer cells. Int J Radiat Oncol Biol Phys 75: 475-481, 2009.

26. Zhou YC, Liu JY, Li J, Zhang J, Xu YQ, Zhang HW, Qiu LB, Ding GR, Su XM, Mei-Shi and Guo GZ: Ionizing radiation promotes migration and invasion of cancer cells through transforming growth factor-beta-mediated epithelial-mesenchymal transition. Int J Radiat Oncol Biol Phys 81: 1530-1537, 2011.

27. Gow MD, Seymour CB, Ryan LA and Mothersill CE: Induction of bystander response in human glioma cells using high-energy electrons: A role for TGF-beta1. Radiat Res 173: 769-778, 2010.

This work is licensed under a Creative Commons Attribution-NonCommercial-NoDerivatives 4.0 International (CC BY-NC-ND 4.0) License. 